thin appendages in the anisochelae. Once captive, the crustaceans were unable to free themselves. They remained struggling for several hours, which indicates that there was no paralysing or toxic secretion. The filament epithelial cells, however, established close contact with the surface of the live prey as early as $1 \mathrm{~h}$ after capture. Intense morphogenetic activity involving extensive cell migration occurred after capture. The implicated filaments became shorter and thicker, frequently becoming entangled. New, thin filaments grew over the prey, which was completely enveloped after one day and digested within a few days. After overfeeding in experimental conditions, a complete reorganization occurred, with a normal appearance being resumed only after several days.

Thus all available evidence shows that the sponge is an effective carnivore. The high frequency of crustaceans found still alive or in various stages of decay, both on the surface and within the bodies of specimens collected in natural conditions, suggests that crustaceans smaller than $1 \mathrm{~mm}$ are the animal's main source of food in the cave.

Are the adaptations and unusual mode of life observed in this sponge living in a specific sublittoral environment shared by other Cladorhizidae in their deep-sea habitats? Their anatomy and histology are poorly known because of the difficulties in collecting and adequately preserving deep-sea animals. Our unpublished observations of several correctly preserved deepwater cladorhizids did confirm the general absence of canals, apertures and choanocyte chambers that intrigued early observers $^{13-15}$. Moreover, lateral expansions provided with hook-shaped spicules are common specialized structures in Cladorhizidae. Small animals are frequently found trapped in specimens collected by trawls. It seems likely, therefore, that the entire family Cladorhizidae has developed non-filter-feeding adaptations. Morphological features indicate that the genera Asbestopluma and Cladorhiza share the same adaptations for the capture of swimming animals with thin appendages; other adaptations may occur in a third genus, Chondrocladia ${ }^{16}$.

These sponges may have other nutrient sources as well. As yet unpublished observations on a Cladorhiza from a cold seep with methane venting, located 4,900 m deep near Barbados, have shown that it is associated with bacteria displaying the morphological characteristics of methanotrophs. Such an association has so far not been described in Porifera, although it has been shown to sustain some deep-sea molluscs and pogonophorans ${ }^{17} 19$.

Our results raise fundamental questions about the validity of characteristics used to distinguish the phyla of lower invertebrates. A sponge is defined as "a sedentary, filter-feeding metazoan which utilizes a single layer of flagellated cells (choanocytes) to pump a unidirectional water current through its body"20. Except for being sedentary, the cave Asbestopluma and presumably all Cladorhizidae lack these basic sponge attributes. In an extreme environment where active filter-feeding has a low yield, cladorhizids have developed a mode of life roughly similar to that of foraminiferans or cnidarians. Their feeding mechanism relies on passive capture of living prey and on transfer of nutrients into the body through intense cell migrations, the analogue of cytoplasmic streaming in foraminiferan pseudopodia. This may be compared to the emergence of macrophagy in abyssal tunicates, also accompanied by a reduction of the filtering system ${ }^{2,3}$ although in Cladorhizidae the result is more extreme, with a main body plan different from Porifera and resembling no other modern anatomical design.

Such a unique body plan would deserve recognition as a distinct phylum, if these animals were not so evidently close relatives of Porifera. Their siliceous spicules show clear similarities to several families of poecilosclerid Demospongiae. The importance of cell mobility and cytological features such as the structure of the external epithelium and the absence of specialized intercellular junctions are also characteristics of Porifera. Given the evidence thus far, we interpret these organisms to be sponges that have deviated from the filtering organization typical of Porifera and developed adaptations that accommodate totally different feeding habits in the still, nutrient-poor deepsea environments.

Received 16 September; accepted 9 November 1994

1. Deep-sea Biology (eds Gage, J. D. \& Tyler, P. A.) (Cambridge Univ. Press, Cambridge, 1991). 2. Monniot, C. Ambio Spec. Rep. 6, 73-74 (1979).

3. Monniot, C. \& Monniot, F. C. r. Acad. Sci. Paris, III 312, 383-388 (1991)

4. Bergquist, P. R. in The Origins and Relationships of Lower Invertebrates, The Systematics Association edn Vol. 28 (eds Morris, S. C. et al.) 14-27 (Clarendon, Oxford, 1985).

5. Lévi, C. in Biology of the Porifera, Symp. zool. Soc. London edn Vol. 25 (ed. Fry, W. G.) 353-364 (Academic, London, 1970).

6. Invertebrate Relationships. Patterns in Animal Evolution (Willmer, P.) (Cambridge Univ. Press, Cambridge, 1990)

7. Reiswig, H. M. J. exp. mar. Biol. Ecol. 14, 231-249 (1974).

8. Reiswig, H. M. Biol. Bull. 141, 568-591 (1971)

9. Boury-Esnault, N., Harmelin, J. G. \& Vacelet, J. La Recherche 24, 848-851 (1993).

10. Vacelet, J., Boury-Esnault, N. \& Harmelin, J. G. Deep-sea Res. 41, 965-973 (1994).

11. Koltun, V. M. (in Russian) Inst. Oceanol. Acad. Sci. U.S.S.R. 86, 165-221 (1970).

12. Wilkinson, C. R. \& Garrone, R. in Nutrition in the Lower Metazoa (eds Smith, D. C. \& Tiffon, Y.) 157-161 (Pergamon, Oxford, New York, 1980).

13. On Some Remarkable Forms of Animal Life from the Great Deeps off the Norwegian Coast (Sars, G. O.) (Brýgger \& Christie, Christiana, 1872).

14. Ridley, S. \& Dendy, A. Rep. Scient. Res. Challenger, Zool. 20, 275 (1887)

15. Lundbeck, W. Danish ingolf-Exp. 6, 1-219 (1905)

16. Tendal, O. S., Barthel, D. \& Tabachnik, K. Deep-sea Newsl. 21, 11-12 (1993).

17. Childress, J. J. et al. Science 233, 1306-1308 (1986).

18. Cavanaugh, C. M. et al. Nature $\mathbf{3 2 5}, 346-348(1987)$.

19. Schmaljohann, R. \& Flügel, H. J. Sarsia 72, 91-98 (1987).

20. Bergquist, P. R. Sponges (Hutchinson, London, 1978).

ACKNOWLEDGEMENTS. We thank G. Bakus, J. Jackson, L. Laubier, C. Lévi, M. Pavans de Ceccatty, S. Pomponi, H. Reiswig, R. van Soest and C. Wilkinson who reviewed the manuscript and gave useful advice, C. Jalong, C. Bézac and I. Mahieu for technicai assistance and C. M. Nafziger for improving the English.

\section{Protection and repair of the nigrostriatal dopaminergic system by GDNF in vivo}

\author{
A. Tomac*, E. Lindqvist, L.-F. H. Lin†, S. O. Ögren*, \\ D. Young $\ddagger$, B. J. Hoffer* \& L. Olson*
}

* Department of Neuroscience, Karolinska Institute,

S-171 77 Stockholm, Sweden

† Synergen Inc., Boulder, Colorado 80301, USA

† Department of Preventive Medicine and Biostatistics,

University of Colorado, Denver, Colorado 80217, USA

GLIAL-CELL-LINE-DERIVED neurotrophic factor (GDNF), a recently cloned new member of the transforming growth factor- $\beta$ superfamily, promotes survival of cultured fetal mesencephalic dopamine neurons ${ }^{1}$ and is expressed in the developing striatum ${ }^{2,3}$. There have, however, been no reports about effects of GDNF in situ. We have used the dopaminergic neurotoxin 1-methyl-4-phenyl-1,2,3,6tetrahydropyridine (MPTP), which produces parkinsonian symptoms in man, to determine whether GDNF might exert protective or regenerative effects in vivo in the adult nigrostriatal dopamine system in C57/B1 mice. GDNF injected over the substantia nigra or in striatum before MPTP potently protects the dopamine system, as shown by numbers of mesencephalic dopamine nerve cell bodies, dopamine nerve terminal densities and dopamine levels. When GDNF is given after MPTP, dopamine levels and fibre densities are significantly restored. In both cases, motor behaviour is increased above normal levels. We conclude that intracerebral GDNF administration exerts both protective and reparative effects on the nigrostriatal dopamine system, which may have implications for the development of new treatment strategies for Parkinson's disease.

The possibility that Parkinson's disease is caused by lack of sufficient 'dopaminotrophic' support and/or the prospect of treating the disease with a neurotrophic factor has led to searches for 'dopaminotrophic' factors. Tissue extracts as well as several known growth factors ${ }^{4}{ }^{10}$, including brain-derived neurotrophic 


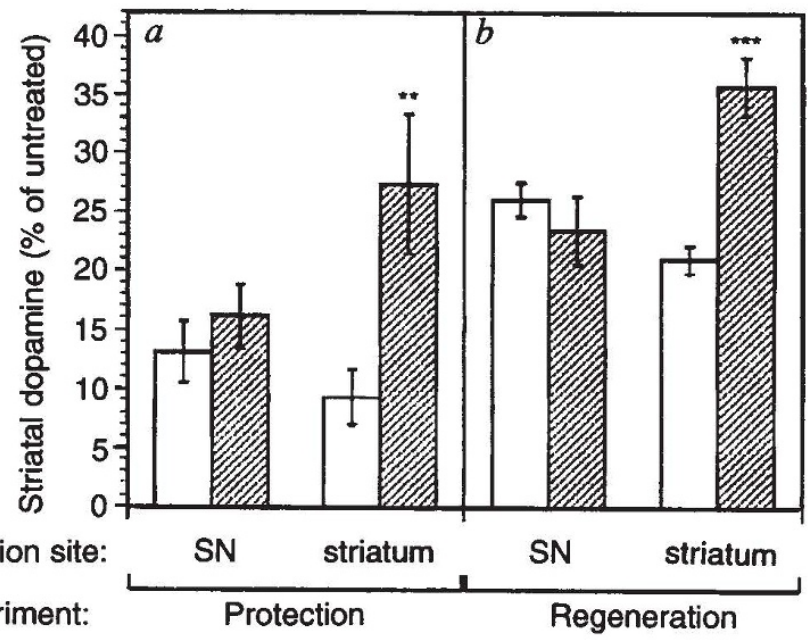

FIG. 1 Striatal dopamine levels in mice given vehicle (open bars) or GDNF (hatched bars) before (a) or after (b) MPTP exposure. Stereotaxic GDNF or vehicle injections were made over the substantia nigra or into the striatum. Dopamine levels \pm s.e.m. in the caudate on the injected side are expressed as percentage of levels in untreated animals. For details of neurochemical measurements, see legend to Table 1. ${ }^{* *} P<0.01,{ }^{* * *} P<0.001$ (ANOVA).

METHODS. C57/BI mice (11-12 weeks) were anaesthesized with halothane, stereotaxically injected with $10 \mu \mathrm{g}$ GDNF in $2 \mu \mathrm{l}$ or $2 \mu \mathrm{l}$ vehicle either $24 \mathrm{~h}$ before, or 7 days or 7 and 16 days after MPTP $\left(40 \mathrm{mg} \mathrm{kg}^{-1}\right.$ for two consecutive days) administration, at the following coordinates: substantia nigra AP: -2.9 ; L: $1.3, \mathrm{DV}:-4.2 \mathrm{~mm}$; striatum: AP: 0.2 , L: 2.0, DV: $-3.8 \mathrm{~mm}$ relative to bregma and the dural surface. Human recombinant GDNF produced in Escherichia coli and refolded ${ }^{1}$ to full biological activity was used. A stock solution of $40.5 \mu \mathrm{g}^{-1}$ GDNF was diluted in PBS and used for intracerebral injections. Animals were killed and brain areas were rapidly dissected and frozen for monoamine determinations ${ }^{13,14}$.

$\begin{array}{lccc}\text { Injection site: } & \text { SN } & \text { striatum } & \text { SN } \\ \text { Experiment: } & \text { Protection } & \text { Regeneration }\end{array}$
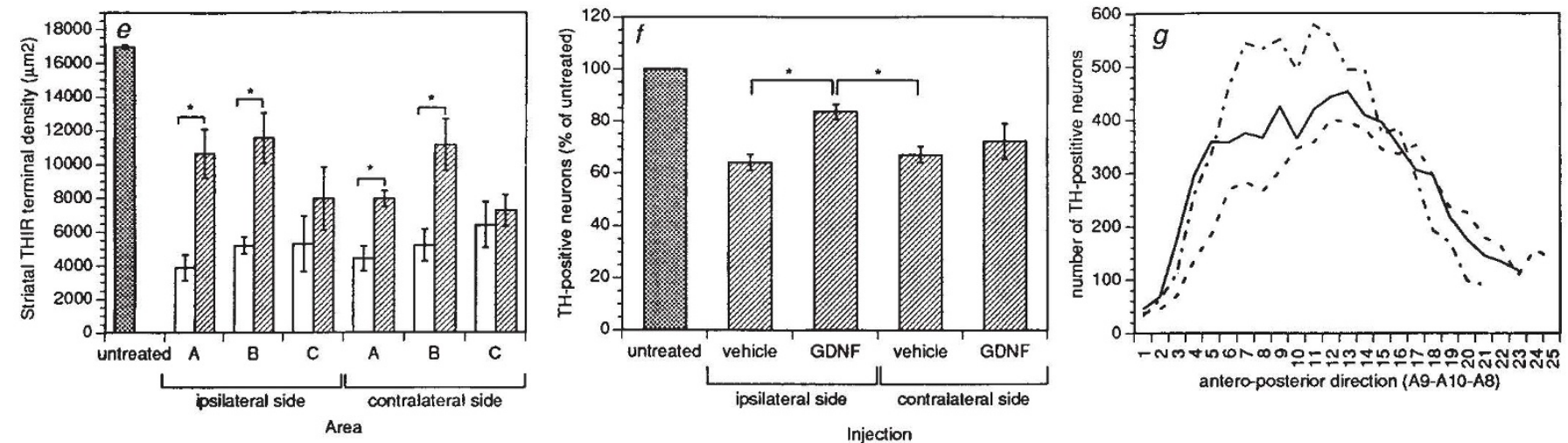

FIG. 2 Tyrosine hydroxylase-positive nerve fibres and cell bodies. a$d$, Photomicrographs of TH-IR fibres in $5-\mu \mathrm{m}$ sections of ipsilateral striatum. Protective experiment: $a$, Control: MPTP-treated animal given a stereotaxic injection of $2 \mu \mathrm{l}$ of vehicle over the substantia nigra. $b$, Animal pretreated with $10 \mu \mathrm{g}$ GDNF over the substantia nigra $24 \mathrm{~h}$ before MPTP exposure. Regenerative experiment: $c$, Control: animals given two stereotaxic injections of $2 \mu \mathrm{l}$ of vehicle into the striatum after MPTP treatment. $d$, Animal given two stereotaxic injections of GDNF into the striatum after MPTP treatment (magnification for $a-d ; \times 100$ ). e, TH-IR fibre density measurements in three areas representing dorsomedial (A), dorsolateral (B) and central (C) parts of the striatum of MPTP-exposed mice, which were pretreated with GDNF (hatched bars) or vehicle injections (white bars). TH terminal density in similarly studied control mice given only saline i.p. was $16,949 \mu \mathrm{m}^{2}$ per unit area (leftmost bar). This density did not show any significant regional variation in untreated mice. $f$, Dopamine nerve cell counts in 3 animals given GDNF and 3 animals given vehicle injections over the substantia nigra area before MPTP exposure. Twenty-five serial $14-\mu \mathrm{m}$ sections at $70-\mu \mathrm{m}$ intervals through the mesencephalic DA cell complex of each brain were used to count all TH-IR nerve cell bodies of groups A8, A9 and A10 separately on the ipsilateral and contralateral sides, generating 490 individual cell group counts. In C57/BI mice, MPTP exposure characteristically causes a loss of DA nerve cell bodies versus control ${ }^{14}$. Although cell losses are most marked in substantia nigra pars compacta ${ }^{14}$, effects of GDNF treatment were also noted in the other major DA cell groups and were not restricted to the injected side. Average total numbers of TH-IR cells, per level and per animal, were calculated. Normal mice in these experiments contained about 17,148 TH-positive cells in the A8A10 area (leftmost bar). MPTP treatment leads to a loss of $30 \%$ of the TH neurons. $f$, Total numbers of DA cells. $g$, Craniocaudal distribution of total numbers of cells per section in untreated mice (dashed and dotted line), GDNF + MPTP treated (solid line) and vehicle + MPTP treated (dashed line) animals.
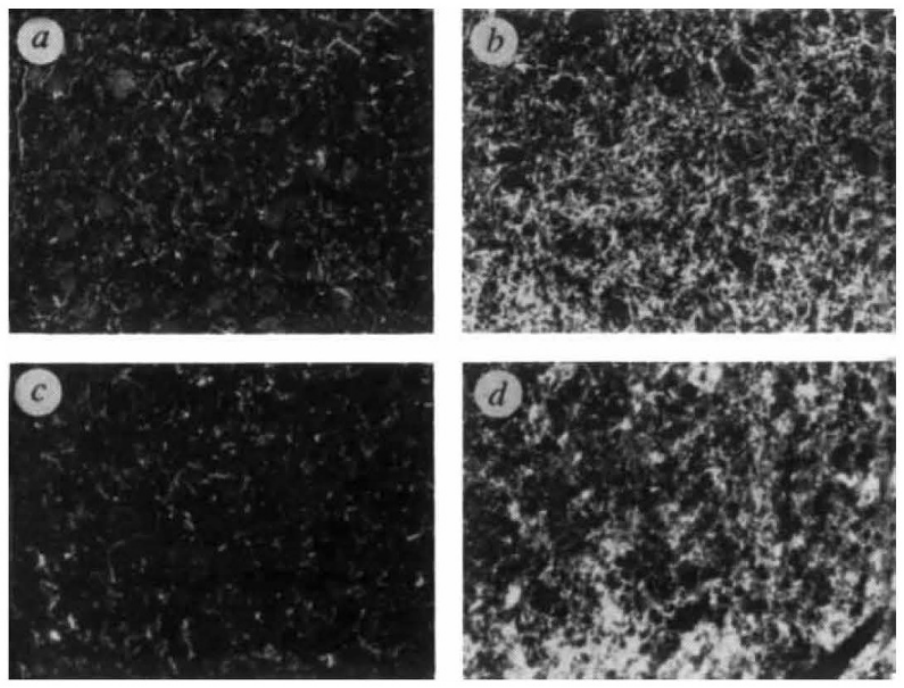

METHODS. Animals were killed by deep anaesthesia, perfused and further processed for immunohistochemistry using TH-antibodies $(\text { Pel-Freeze })^{2}$. Using a Peltier-cooled CCD camera (Kodak), images were digitized and analysed (MicroGOP Contextvision, SUN Microsystem SparcStation 5 with Sun Video real time video capture and compression subsystem). Density of immunoreactive fibres was calculated averaging three sections per animal. Five animals per group ${ }^{*} P<0.05,{ }^{* *} P<0.01$ and ${ }^{* * *} P<0.001$, compared with vehicle-treated (control) animals (ANOVA). 
TABLE 1 Reverse-phase HPLC data

\begin{tabular}{|c|c|c|c|c|c|c|c|}
\hline \multicolumn{2}{|l|}{ Group area } & $\mathrm{DA}$ & HVA & DOPAC & $5-\mathrm{HT}$ & 5-HIAA & NA \\
\hline $\begin{array}{l}\text { GDNF treatm } \\
\text { MPTP s.c. }+ \\
\text { veh(SN) } \\
n=13\end{array}$ & $\begin{array}{l}\text { follow } \\
\text { SN } \\
\text { CPu } \\
\text { tub } \\
\text { acc }\end{array}$ & $\begin{array}{l}\text { MPTP } \\
473 \pm 68 \\
1,783 \pm 348 \\
2,068 \pm 187 \\
6,117 \pm 259\end{array}$ & $\begin{array}{c}340 \pm 57 \\
583 \pm 94 \\
325 \pm 15 \\
1,933 \pm 970\end{array}$ & $\begin{array}{l}104 \pm 12 \\
223 \pm 43 \\
311 \pm 21 \\
959 \pm 39\end{array}$ & $\begin{aligned} 1,369 & \pm 75 \\
277 & \pm 20 \\
815 & \pm 66 \\
1,455 & \pm 756\end{aligned}$ & $\begin{array}{l}971 \pm 57 \\
390 \pm 37 \\
346 \pm 15 \\
806 \pm 75\end{array}$ & $\begin{array}{l}432 \pm 38 \\
126 \pm 24 \\
111 \pm 14 \\
988 \pm 161\end{array}$ \\
\hline $\begin{array}{l}\text { MPTP s.c. }+ \\
\text { GDNF(SN) } \\
n=13\end{array}$ & $\begin{array}{l}\mathrm{SN} \\
\mathrm{CPu} \\
\text { tub } \\
\text { acc }\end{array}$ & $\begin{array}{c}785 \pm 120^{* *} \\
2,193 \pm 372 \\
3,010 \pm 697 \\
8,618 \pm 583\end{array}$ & $\begin{array}{c}577 \pm 81^{* *} \\
918 \pm 142 \\
661 \pm 104^{* *} \\
1,646 \pm 108\end{array}$ & $\begin{aligned} 191 & \pm 29^{* *} \\
381 & \pm 42^{*} \\
598 & \pm 141^{*} \\
1,162 & \pm 76\end{aligned}$ & $\begin{array}{c}1,425 \pm 103 \\
322 \pm 15 \\
955 \pm 15 \\
754 \pm 10\end{array}$ & $\begin{array}{c}1,171 \pm 108 \\
482 \pm 39 \\
442 \pm 22 \\
991 \pm 42\end{array}$ & $\begin{array}{c}603 \pm 41^{* *} \\
119 \pm 22 \\
109 \pm 28 \\
1,562 \pm 692\end{array}$ \\
\hline $\begin{array}{l}\text { MPTP s.c. + } \\
\text { veh(CPu) } \\
n=6\end{array}$ & $\begin{array}{l}\mathrm{SN} \\
\mathrm{CPu} \\
\text { tub } \\
\text { acc }\end{array}$ & $\begin{array}{c}318 \pm 21 \\
1,273 \pm 309 \\
2,712 \pm 174 \\
4,915 \pm 663\end{array}$ & $\begin{array}{l}212 \pm 16 \\
539 \pm 59 \\
375 \pm 17 \\
926 \pm 367\end{array}$ & $\begin{array}{c}88 \pm 4 \\
172 \pm 24 \\
329 \pm 22 \\
500 \pm 71\end{array}$ & $\begin{array}{c}1,450 \pm 38 \\
230 \pm 9 \\
837 \pm 22 \\
579 \pm 87\end{array}$ & $\begin{array}{l}923 \pm 103 \\
370 \pm 39 \\
320 \pm 25 \\
586 \pm 78\end{array}$ & $\begin{array}{c}417 \pm 24 \\
\text { ND } \\
104 \pm 15 \\
657 \pm 222\end{array}$ \\
\hline $\begin{array}{l}\text { MPTP s.c. }+ \\
\text { GDNF(CPu) } \\
n=6\end{array}$ & $\begin{array}{l}\mathrm{SN} \\
\mathrm{CPu} \\
\text { tub } \\
\mathrm{acc}\end{array}$ & $\begin{aligned} 914 & \pm 150^{* *} \\
3,720 & \pm 797^{* *} \\
3,624 & \pm 276^{*} \\
11,338 & \pm 2733^{* *}\end{aligned}$ & $\begin{aligned} 617 & \pm 86^{* * *} \\
1,847 & \pm 280^{* * *} \\
777 & \pm 78^{* * *} \\
2,091 & \pm 213\end{aligned}$ & $\begin{array}{c}286 \pm 49^{* * *} \\
768 \pm 139^{* * *} \\
723 \pm 95^{* * *} \\
1,652 \pm 236^{* * *}\end{array}$ & $\begin{array}{c}1,748 \pm 75^{*} \\
288 \pm 13^{*} \\
929 \pm 73 \\
786 \pm 117\end{array}$ & $\begin{aligned} 1,195 & \pm 113 \\
498 & \pm 38^{*} \\
438 & \pm 38^{* *} \\
971 & \pm 188^{*}\end{aligned}$ & $\begin{aligned} 555 & \pm 54 \\
67 & \pm 42 \\
121 & \pm 25 \\
990 & \pm 238\end{aligned}$ \\
\hline $\begin{array}{l}\text { Controls for } \\
\text { Saline s.c. } \\
n=4\end{array}$ & $\begin{array}{l}\text { ective } \\
\text { SN } \\
\text { CPu } \\
\text { tub } \\
\text { acc }\end{array}$ & 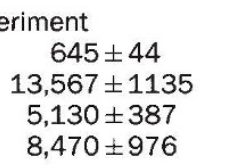 & $\begin{aligned} 370 & \pm 14 \\
1,945 & \pm 242 \\
613 & \pm 19 \\
1,221 & \pm 162\end{aligned}$ & $\begin{array}{c}177 \pm 15 \\
956 \pm 100 \\
565 \pm 56 \\
1,177 \pm 208\end{array}$ & $\begin{array}{c}1,513 \pm 170 \\
264 \pm 11 \\
893 \pm 61 \\
723 \pm 44\end{array}$ & $\begin{array}{l}817 \pm 55 \\
311 \pm 34 \\
298 \pm 10 \\
662 \pm 70\end{array}$ & $\begin{array}{c}411 \pm 35 \\
167 \pm 58 \\
112 \pm 27 \\
1,397 \pm 177\end{array}$ \\
\hline $\begin{array}{l}\text { MPTP follow } \\
\text { MPTP S.c. + } \\
\text { veh(SN) } \\
n=5\end{array}$ & $\begin{array}{l}\text { y GDN } \\
\text { SN } \\
\text { CPu } \\
\text { tub } \\
\text { acc }\end{array}$ & $\begin{array}{l}\text { eatment } \\
\qquad 558 \pm 72 \\
4,656 \pm 252 \\
3,873 \pm 208 \\
8,851 \pm 977\end{array}$ & $\begin{aligned} 257 & \pm 43 \\
940 & \pm 58 \\
367 & \pm 21 \\
3,089 & \pm 574\end{aligned}$ & $\begin{array}{c}143 \pm 21 \\
508 \pm 28 \\
352 \pm 28 \\
2,053 \pm 324\end{array}$ & $\begin{array}{c}1,662 \pm 118 \\
348 \pm 12 \\
909 \pm 41 \\
703 \pm 84\end{array}$ & $\begin{array}{r}798 \pm 70 \\
350 \pm 13 \\
276 \pm 22 \\
1,214 \pm 97\end{array}$ & $\begin{array}{c}501 \pm 34 \\
100 \pm 19 \\
158 \pm 13 \\
1,107 \pm 182\end{array}$ \\
\hline $\begin{array}{l}\text { MPTP s.c. }+ \\
\text { GDNF(SN) } \\
n=7\end{array}$ & $\begin{array}{l}\mathrm{SN} \\
\mathrm{CPu} \\
\text { tub } \\
\mathrm{acc}\end{array}$ & $\begin{aligned} 913 & \pm 126^{* *} \\
4,172 & \pm 521 \\
4,877 & \pm 178^{* *} \\
9,448 & \pm 1207\end{aligned}$ & $\begin{array}{c}350 \pm 37^{*} \\
899 \pm 58 \\
357 \pm 21 \\
3,925 \pm 702\end{array}$ & $\begin{array}{c}222 \pm 32^{*} \\
429 \pm 56 \\
463 \pm 30 \\
2,697 \pm 226\end{array}$ & $\begin{array}{c}1,906 \pm 139 \\
392 \pm 22 \\
999 \pm 35 \\
779 \pm 92\end{array}$ & $\begin{aligned} 1,024 & \pm 119 \\
426 & \pm 12^{* *} \\
360 & \pm 19 \\
1,799 & \pm 181^{* *}\end{aligned}$ & $\begin{aligned} 684 & \pm 63^{*} \\
83 & \pm 6 \\
190 & \pm 18 \\
1,253 & \pm 219\end{aligned}$ \\
\hline $\begin{array}{l}\text { MPTP s.c. }+ \\
\text { veh(CPu) } \\
n=8\end{array}$ & $\begin{array}{l}\text { SN } \\
\text { CPu } \\
\text { tub } \\
\text { acc }\end{array}$ & $\begin{array}{c}529 \pm 61 \\
3,765 \pm 220 \\
3,226 \pm 193 \\
9,301 \pm 1521\end{array}$ & $\begin{array}{c}258 \pm 22 \\
951 \pm 48 \\
263 \pm 15 \\
3,139 \pm 470\end{array}$ & $\begin{array}{c}165 \pm 18 \\
627 \pm 72 \\
492 \pm 72 \\
1,616 \pm 345\end{array}$ & $\begin{array}{c}1,266 \pm 225 \\
317 \pm 16 \\
770 \pm 40 \\
640 \pm 97\end{array}$ & $\begin{array}{c}946 \pm 197 \\
420 \pm 16 \\
364 \pm 42 \\
1,098 \pm 142\end{array}$ & $\begin{array}{c}453 \pm 88 \\
101 \pm 8 \\
242 \pm 32 \\
1,271 \pm 319\end{array}$ \\
\hline $\begin{array}{l}\text { MPTP s.c. }+ \\
\text { GDNF(CPu) } \\
n=8\end{array}$ & $\begin{array}{l}\mathrm{SN} \\
\mathrm{CPu} \\
\text { tub } \\
\text { acc }\end{array}$ & $\begin{array}{l}1,027 \pm 379^{* * *} \\
6,394 \pm 444^{* * *} \\
3,849 \pm 146 \\
8,511 \pm 1219\end{array}$ & $\begin{aligned} 463 & \pm 36^{* * *} \\
1,441 & \pm 85^{* * *} \\
315 & \pm 25 \\
2,751 & \pm 184\end{aligned}$ & $\begin{aligned} 281 & \pm 30^{* *} \\
863 & \pm 73^{* *} \\
412 & \pm 34 \\
1,053 & \pm 122\end{aligned}$ & $\begin{array}{c}1,879 \pm 100^{* * *} \\
396 \pm 38^{*} \\
888 \pm 33^{*} \\
794 \pm 64\end{array}$ & $\begin{array}{r}1,011 \pm 51 \\
447 \pm 23 \\
346 \pm 21 \\
941 \pm 47\end{array}$ & $\begin{array}{c}662 \pm 54^{*} \\
115 \pm 10 \\
1,93 \pm 30 \\
1,342 \pm 284\end{array}$ \\
\hline $\begin{array}{l}\text { Controls for } \\
\text { Saline s.c. } \\
n=5\end{array}$ & $\begin{array}{l}\text { arative } \\
\text { SN } \\
\text { CPu } \\
\text { tub } \\
\text { acc }\end{array}$ & $\begin{array}{l}\text { eriment } \\
578 \pm 109 \\
17,868 \pm 470 \\
6,457 \pm 452 \\
11,655 \pm 2371\end{array}$ & $\begin{aligned} 312 & \pm 25 \\
1,693 & \pm 74 \\
517 & \pm 44 \\
4,754 & \pm 2305\end{aligned}$ & $\begin{array}{c}169 \pm 21 \\
1,576 \pm 144 \\
989 \pm 91 \\
2,108 \pm 454\end{array}$ & $\begin{array}{r}1,364 \pm 86 \\
333 \pm 24 \\
791 \pm 31 \\
859 \pm 60\end{array}$ & $\begin{array}{c}702 \pm 18 \\
311 \pm 21 \\
327 \pm 29 \\
1,432 \pm 305\end{array}$ & $\begin{array}{c}437 \pm 57 \\
153 \pm 3 \\
188 \pm 24 \\
1,741 \pm 756\end{array}$ \\
\hline
\end{tabular}

Levels (mean $\mathrm{ng} \mathrm{g}^{-1}$ wet weight \pm s.e.m.) of dopamine (DA), 5-hydroxytryptamine (5-HT) and noradrenaline (NA), as well as the dopamine metabolites homovanillic acid (HVA) and 3,4-dihydroxyphenylacetic acid (DOPAC) and the 5-HT metabolite 5-hydroxyindoleacetic acid (5-HIAA) in the substantia nigra (SN), the caudate-putamen (CPu), tuberculum olfactorium (tub) and nucleus accumbens (acc), as determined by reverse-phase $\mathrm{HPLC}^{13,14}$. In the protection experiments, MPTP treatment led to striatal DA levels which were 13 or $9 \%$, respectively, of levels in saline-treated animals in the two control groups (MPTP + vehicle (veh) into SN, MPTP + vehicle into CPu) 6 days after the first subcutaneous (s.c.) MPTP injection when the mice were 12-13 weeks old. This depletion was paralleled by a marked loss of striatal TH-IR fibres and an increased DA turnover, as indicated by the increased HVA/DA ratio. When GDNF was given instead after MPTP, animals were not killed until 26 days after the first MPTP injection. Basal levels of striatal DA were higher in these 15-16-week-old saline-injected animals than in the 12-13-wsek-old mice above. DA levels in the two MPTP-treated control groups were 26 and $21 \%$ of controls, respectively. The number of TH-IR fibres was markedly reduced and the HVA/DA ratio was roughly doubled. Thus striatal DA levels increase with age in both saline and MPTP-treated mice. While $2 \times 40 \mathrm{mg} \mathrm{kg}^{-1} \mathrm{MPTP}$ leads to long-lasting DA depletions, a modest degree of recovery appears to occur from day 6 to day 26 after MPTP. ${ }^{*} P<0.05$, ${ }^{* *} P<0.01$, ${ }^{* * *} P<0.001$ (ANOVA).

factor $(\mathrm{BDNF})^{5}$, exert variable or modest degrees of dopaminotrophic activity. However, targeted disruption of the BDNF gene does not lead to any apparent loss of dopamine neurons ${ }^{11}$. GDNF exerts a trophic influence on grafted fetal mesencephalic dopamine neurons ${ }^{2}$, suggesting that exogenous GDNF could be efficacious in vivo. We used the neurotoxin, MPTP, which leads to a well characterized ${ }^{12} 14$ long-term loss of dopaminergic circuitry in $\mathrm{C} 57 / \mathrm{Bl}$ mice, to investigate whether pretreatment with GDNF might protect adult dopamine neurons from neurotoxic damage, and furthermore, whether treatment with GDNF after MPTP-induced degeneration might lead to anatomical and functional recovery.
Adult male mice (11-12 weeks, C57/B16) were treated with MPTP (40 $\mathrm{mg} \mathrm{kg}^{-1}$ subcutaneously (s.c.)) for 2 consecutive days. The mouse strain and age, as well as the treatment regimen, was chosen to lead to marked and long-lasting dopamine depletion in striatum ${ }^{14,15}$, and a loss of mesencephalic dopamine cell bodies $^{14}$. To study if GDNF could protect against the MPTPinduced damage, mice were given unilateral stereotaxic injections of $10 \mu \mathrm{g}$ GDNF in a volume of $2 \mu \mathrm{l}$, or $2 \mu \mathrm{l}$ vehicle directly above substantia nigra or into striatum $24 \mathrm{~h}$ before the first MPTP injection. These animals were killed 7 days after MPTP. To study possible reparative effects, GDNF was given 7 , or 7 and 16 days after MPTP using the same intracerebral doses 
and coordinates as for the protective protocol. These mice were monitored for 18 days before killing. A total of 174 mice divided into 6 different groups for both the protective and the regenerative experiments were used to study levels of catecholamines, 5-hydroxytryptamine (5-HT) and metabolites, motor behaviour, as well as dopamine cells and nerve fibre densities (protection experiments: biochemistry: $n=38$, histochemistry: $n=51$; regeneration experiments : biochemistry: $n=50$, histochemistry: $n=35$ ). In addition, control experiments were done to determine normal cell numbers (determined by staining for tyrosine hydroxylase) and nerve fibre densities in untreated mice $(n=4)$, the effects of GDNF in normal mice $(n=13)$, and the behavioural effects of a higher dose of MPTP $(n=12)$.

When GDNF was given before MPTP, the dopamine levels were noticeably protected on the side of the intracranial injection both in substantia nigra (Table 1) and striatum (Fig. 1, Table 1) following a striatal injection of GDNF. After a nigral GDNF injection, dopamine levels in the substantia nigra area were partially protected (Table 1), whereas levels in striatum remained low (Fig. 1, Table 1). These protective effects were also reflected in increased levels of the dopamine metabolites homovanillic acid (HVA) and 3,4-dihydroxyphenylacetic acid (DOPAC) (Table 1). Smaller increases in 5-HT and 5-hydroxyindoleacetic acid (5-HIAA) were also noted, whereas noradrenaline levels appeared less influenced (Table 1). GDNF injected 1 week after MPTP was able partially to restore dopamine levels. These effects were of somewhat smaller magnitude than the protective effects of GDNF, and seen both in substantia nigra and striatum following an intrastriatal injection (Fig. 1, Table 1) but only in substantia nigra following a GDNF injection above the nigra (Table 1). Transmitter level changes in two other areas with a rich dopamine innervation, tuberculum olfactorium and nucleus accumbens, were similar to those found in striatum, although often of lesser magnitude (Table 1). For both intrastriatal and nigral injections of GDNF, catecholamines and metabolites in contralateral striatal and nigral tissue showed smaller changes in a direction similar to those seen ipsilaterally, particularly in the contralateral substantia nigra after nigral injections (data not shown). Because the nigrostriatal dopamine system is uncrossed, we interpret these effects as due to diffusion of GDNF across the midline following mesencephalic injections. In one set of control experiments GDNF was injected unilaterally into the striatum of normal mice. This treatment did not lead to any significant changes in dopamine levels (data not shown) or dopamine metabolites (data not shown) in striatum or in substantia nigra.

Tyrosine hydroxylase immunohistochemistry was used to visualize catecholaminergic neurons, and monitor GDNF-induced changes at the cellular level. Pretreatment with GDNF led to a marked and highly significant preservation of striatal TH-immunoreactive (IR) nerve terminals on the injected side of the brain (Fig. $2 a, b, e$ ). Cell counts revealed a higher number of TH-IR cell bodies in the mesencephalic dopamine cell complex (groups $\mathrm{A} 8-\mathrm{A} 10^{16}$, including substantia nigra pars compacta) in the GDNF-pretreated mice (Fig. $2 f, g$ ). Although effects were noted bilaterally, cell numbers on the GDNF-injected side were significantly higher than on the contralateral side (average side difference per section: GDNF $22.5 \pm 15.1$, control $3.3 \pm 6.8$; $P<0.05$, two-tailed $t$-test). In line with the results from measurements of dopamine levels, the effect of a single injection of GDNF in striatum 1 week after MPTP on TH-IR terminals was less marked. However, when two GDNF injections were given after MPTP, the density of striatal TH-IR nerve fibres was markedly increased (Fig. 2c, $d$ ).

Recordings of three measures of motor activity that are thought to reflect basal ganglia dopamine transmission ${ }^{17}$ (loco-
FIG. 3 Motor behaviour of mice given intracranial GDNF (solid line) or vehicle (dashed line) injections before or after MPTP exposure. The curves illustrate locomotion, motility and rearing over a 60 -min test period from two (protective) or three (regenerative) pooled experiments, each with 4-6 mice per treatment group. Vertical bars indicate s.e.m. at each 5 min time point. $a-c$, Data from protective experiments studied 6 days after the first MPTP injection; $d-f$, data from regenerative experiments 11 days after the first MPTP injection. All groups shown were given injections of GDNF or vehicle in striatum, except $c$, where the injections were placed over substantia nigra. A likelihood ratio test (LRT) was used to find the 'best-fitting' models for the 2 treatment groups simultaneously. The approach used is appropriate for repeated measures data, accounting for variability between mice as well as variability between multiple observations on the same mice. GDNF- and vehicle-injected mice were significantly different in all comparisons (a, b, c, e: $P<0.001 ; d, f: P<0.03)$. The MPTP dose $\left(2 \times 40 \mathrm{mg} \mathrm{kg}^{-1}\right)$ was chosen to spare enough of the nigrostriatal DA system to act as a substrate for GDNF in the regeneration experiment. For comparative reasons the same treatment was chosen for the protection experiment. Although this treatment causes marked and highly significant decreases of DA levels and corresponding losses of DA nerve terminals, the remaining DA innervation allows a fairly 'normal' behavioural repertoire in the mice under the present unstressed conditions. Control mice did not differ significantly from the mice given $2 \times 40 \mathrm{mg} \mathrm{kg}^{-1}$ MPTP (data not shown). However, separate control experiments demonstrated that rearing (regarded as the most DA-dependent of these activity measures chosen) was reduced to $27 \%$ of control $(59 \pm 33, n=5$ and $217 \pm 48, n=13)$ when the dose of MPTP was increased to $2 \times 50 \mathrm{mg} \mathrm{kg}^{1}$.
Pre- GDNF treatment
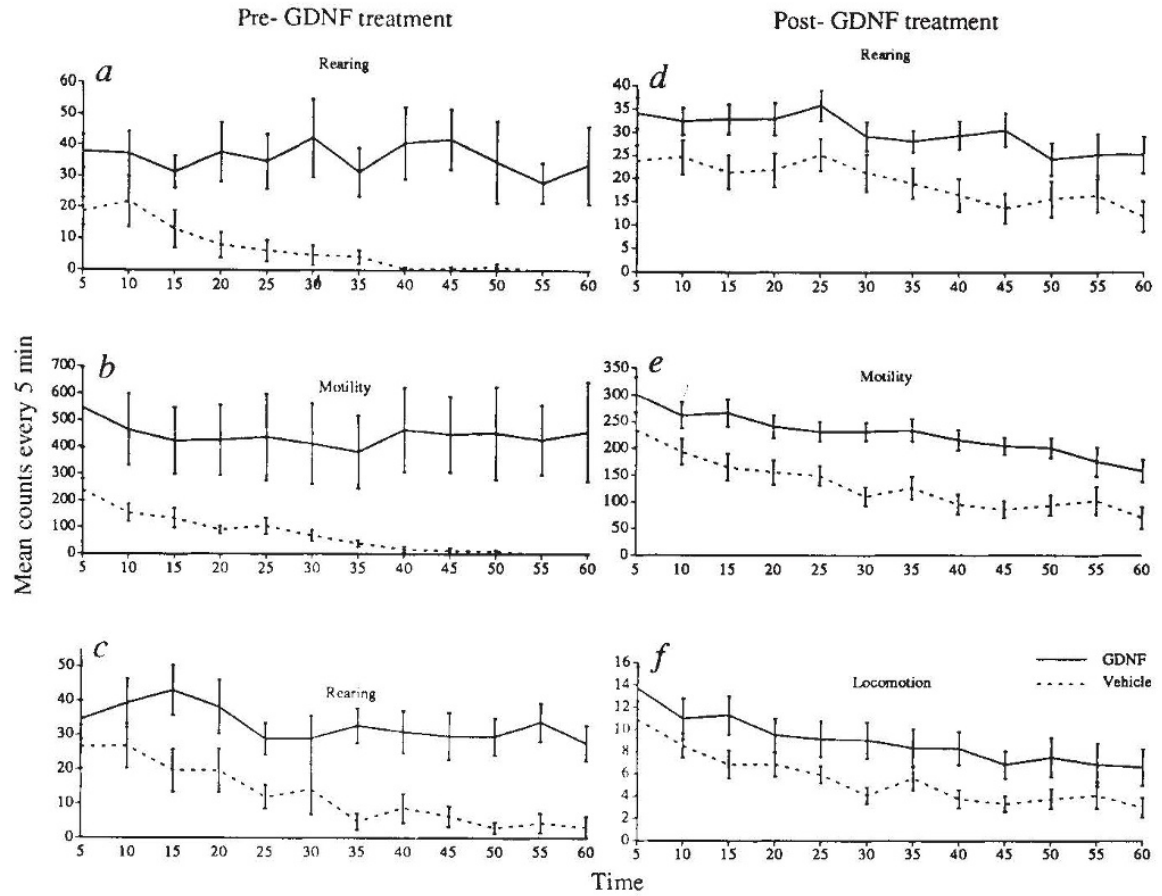

METHODS. Twelve locomotor cages equipped with an array of both horizontal and vertical photocell detectors were used. Locomotion, motility and rearing (vertical activity) were simultaneously recorded by a computerized system using infrared photocells to detect the movements of the mice ${ }^{17}$. Motility is defined as a movement covering a distance of $4 \mathrm{~cm}$ in any direction, and locomotion is defined as a movement covering 8 photocells or $32 \mathrm{~cm}$. Photocells located $9 \mathrm{~cm}$ over the cage floor detected the number of times the mouse stood on its hindlimbs (rearing). 
motion, rearing and motility) showed that GDNF given either before or after MPTP was able to significantly increase motor activity scores as compared to animals treated with MPTP and given vehicle intracranially. Indeed, these behaviours were significantly incremented over levels seen in untreated mice. Figure 3 illustrates increases in motor performance parameters elicited by a single dose of GDNF given before $(a-c)$ or after $(d-f)$ MPTP; Fig. $3 c$ shows data from mice injected over the substantia nigra. All other plots are from intrastriatal injections.

The present results provide the first evidence, to our knowledge, that GDNF can effectively protect midbrain dopamine circuits from the toxic effects of MPTP in vivo and also exert a normalizing, regenerative effect when given after MPTP. We have provided biochemical, histochemical and behavioural evidence consistent with a positive role for GDNF in adult dopamine neurons. The observation that better effects were found in the protective experiments when GDNF was injected in striatum, and that in the regenerative experiment GDNF injected over the nigra area was unable to induce sprouting in striatum, suggests that GDNF might act as a typical target-derived factor. Thus, if GDNF is normally synthesized in striatum one should predict that exogenous GDNF would be more potent when injected into the vicinity of the striatal dopamine nerve terminals. The biochemical, histochemical and behavioural changes induced by GDNF correlate well in all protocols, except for the effects of nigral injections in the protective experiment. In this situation, motor activity and striatal TH-IR are increased, despite no significant increment in striatal dopamine levels. The mechanism here may be analogous to our preliminary studies in nonlesioned rats, where unilateral nigral injections of GDNF elicit a twofold increase in striatal TH-IR and a threefold increase in striatal dopamine turnover, but no significant changes in striatal dopamine levels ${ }^{18}$. Levels of GDNF mRNA in striatum are apparently not regulated by the nigrostriatal dopamine input because no increase is found after 6-hydroxydopamine-induced denervation $^{2}$. Instead, GDNF mRNA levels in striatum might be regulated by the excitatory cortical input ${ }^{19}$. A similar relationship has been suggested for glutamatergic inputs to hippocampus ${ }^{20}$. GDNF mRNA is also found in other areas of the developing rodent such as thalamus, the cerebellar anlage, the cingulate cortex, the pineal gland, neurons of Clark's column in the spinal cord ${ }^{2}$ and adult olfactory tubercle. Although the presence of GDNF synthesis in areas outside the nigrostriatal system suggests additional roles for this new trophic factor in the central nervous system ${ }^{21}$, these experiments have demonstrated that local intracerebral treatment with GDNF can offer significant protection of the nigrostriatal dopamine system from the deleterious effects of the specific neurotoxin MPTP and even induce regeneration of dopamine nerve terminals in adult individuals after MPTP treatment.

\footnotetext{
Received 19 July; accepted 23 November 1994.

1. Lin, L.-F., Doherty, D., Lile, J., Bektesh, S. \& Collins, F. Science 260, 1130-1132 (1993). 2. Strömberg, I. et al. Expl Neurol. 124, 401-412 (1993).

3. Schaar, D. G. Sieber, B. A. Dreyfus, C. F. \& Black, I. B. Expl Neurot 124, 368-371 (1993).

3. Schaar, D. G., Sieber, B. A., Dreyfus, C. F. \& Black, I. B. Expl Neurol.

4. Beck, K., Knüsel, B. \& Hefti, F. Neuroscience 52,

6. Spina, M., Squinto, S., Miller, J., Lindsay, R. \& Hyman, C. J. Neurochem. 59, 99-106 (1992).

7. Nikkhah, G. et al. Expl Brain Res. 92, 516-523 (1993).

8. Ferrari, G., Toffano, G. \& Skaper, S. J. Neurosci. Res. 30, 493-497 (1.991)

9. Magal, E., Burnham, P., Varon, S. \& Louis, J.-C. Neuroscience 52, 867-881 (1993).

10. Otto, D. \& Unsicker, K. J. Neurosci. 10, 1912-1921 (1990).

11. Jones, K. R., Farinas, I., Backus, C. \& Reichardt, L. F. Cell 76, 989-999 (1994).

12. Heikkila, R. E., Hess, A. \& Duvoisin, R. C. Science 224, 1451-1453 (1984).

13. Jonsson, G. et al. Naunyn Schmiedebergs Arch. Pharmac. 331, 1-6 (1985).

14. Sundström, E., Strömberg, I., Tsutsumi, T., Olson, L. \& Jonsson, G. Brain Res. 405, 26-38 Sundström, E., Strömberg, I., Tsutsumi, T., Olson, L. \& Jonsson, G. Brain Res.
(1987).

15. Sundström, E., Fredriksson, A. \& Archer, T. Brain Res. 528, 181-188 (1990).

16. Dahlström, A. \& Fuxe, K. Acta physiol. scand. 62, 1-55 (1964).

17. Ögren, S., Köhler, C., Fuxe, K. \& Ängeby, K. in Dopaminergic Ergot Derivatives and Motor Function (eds Fuxe, K. \& Calne, D.) 187-205 (Pergamon, New York, 1979).

18. Hudson, J. et al. Soc Neurosci. Abstr. 19, 652 (1993).

19. Schmidt-Kastner, R. et al. Molec. Brain Res. 26, 325-330 (1994).

19. Schmidt-Kastner, R. et al. Molec. Brain Res. 26, 325-33

21. Henderson, C. et al. Science 266, 1062-1064 (1994).
}

ACKNOWLEDGEMENTS. We thank 1. Engqvist for editorial assistance and S. Eken and S. Almström for technical assistance. This work was supported by grants from the Swedish MRC and the USPHS.

\section{Mesencephalic dopaminergic neurons protected by GDNF from axotomy-induced degeneration in the adult brain}

\author{
Klaus D. Beck, Janet Valverde, Tajrena Alexl*, \\ Krls Poulsen, Barbara Moffat, Richard A. Vandlen, \\ Arnon Rosenthal \& Franz Hefti
}

Departments of Neuroscience, Protein Chemistry and Cell Genetics, Genentech Inc., South San Francisco, California 94080, USA

*Andrus Gerontology Center, University of Southern California, Los Angeles, California 90089, USA

GLIAL-CELL-LINE-DERIVED neurotrophic factor (GDNF) promotes survival of embryonic dopaminergic neurons in culture ${ }^{i}$, and its expression pattern suggests a role as a transient target-derived trophic factor for dopaminergic neurons of the substantia nigra ${ }^{2-4}$. These neurons participate in the control of motor activity, emotional status and cognition', and they degenerate in Parkinson's disease for unknown reasons. To test whether GDNF has a trophic effect on dopaminergic neurons in the adult brain, we used a rat model in which these neurons are induced to degenerate by transecting their axons within the medial forebrain bundle ${ }^{6}$. We report here that axotomy resulted in loss of half the tyrosine hydroxylaseexpressing neurons in the substantia nigra. This loss was largely prevented by repeated injections of GDNF adjacent to the substantia nigra. Our findings suggest that GDNF or related molecules may be useful for the treatment of Parkinson's disease.
Rat recombinant ( $\mathrm{rr}$ ) GDNF was produced as described ${ }^{1}$ and its activity was tested in embryonic mesencephalic cultures enriched for dopaminergic neurons ${ }^{7}$ (Fig. 1a). Fourteen days after medial forebrain bundle (MFB) transection the number of neurons immunopositive for tyrosine hydroxylase (TH), the transmitter-specific marker of dopaminergic neurons, was reduced in the substantia nigra to $52.6 \%$ of the unlesioned contralateral side (Figs $1 b, 2$ and Table 1). In contrast, rats receiving daily injections of rrGDNF $(60 \mu \mathrm{g}$ total) showed survival of $84.6 \%$ of dopaminergic neurons (Figs $1 b, 2$, Table 1). Unlesioned rats which were injected identically to MFB-lesioned rats through implanted cannulas did not show a difference in the number of TH-immunopositive neurons detected on both sides (Table 1). The size of mesencephalic TH-immunopositive cell bodies was unaffected by rrGDNF administration (cytochrome$c$-injected rats, control side: $90.3 \pm 6.1 \mu \mathrm{m}^{2}$, lesioned side: $89.7 \pm 3.5 \mu \mathrm{m}^{2}$; rrGDNF-injected rats, control side: $89.1 \pm$ $3.7 \mu \mathrm{m}^{2}$, lesioned side : $88.2 \pm 4.5 \mu \mathrm{m}^{2}$; means \pm s.e.m. of $20 \mathrm{ran}$ domly selected $\mathrm{TH}$-positive neurons in the A9 area from each of 8 rats injected with cytochrome $c$ and rrGDNF; analysed using a computerized image analysis system) and there were no changes in TH-immunostaining intensity. The absence of any changes in these parameters might be due to the fact that 14 days after the MFB lesions the axotomy-induced degeneration of nigral dopaminergic neurons is completed ${ }^{8}$.

Analysis of the anteroposterior distribution of dopaminergic neurons in the mesencephalon showed that rrGDNF protected dopamincrgic neurons located at different distances from the axotomy to a similar degree (Fig. $1 b$ ). Less than maximal protection was observed close to the injection site, probably reflecting nonspecific damage of dopaminergic neurons close to the tip of 